\title{
Challenges of Female Nurses in Disasters: A Qualitative Study
}

\author{
Negar Pourvakhshoori ${ }^{1}$, Kian Norouzi ${ }^{1}$, Fazlollah Ahmadi², Mohammad Ali Hosseini ${ }^{3}$, Hamid Reza Khankeh ${ }^{3,4 *}$ \\ 1. Department of Nursing, University of Social Welfare \& Rehabilitation Sciences, Tehran, Iran. \\ 2. Department of Nursing, School of Medical Sciences, Tarbiat Modares University, Tehran, Iran. \\ 3. Department of Health in Emergencies and Disasters, University of Social Welfare \& Rehabilitation Sciences, Tehran, Iran. \\ 4. Department of Clinical Science and Education, Karolinska Institute, Stockholm, Sweden.
}

Cttation: Pourvakhshoori N, Norouzi K, Ahmadi F, Hosseini MA, Khankeh HR. Challenges of Female Nurses in Disasters: A Qualitative Study. Health in Emergencies and Disasters Quarterly. 2016; 2(1):5-12.

: https://doi.org/10.18869/nrip.hdq.2.1.5

\section{Article info:}

Received: 21 Mar. 2016

Accepted: 10 Aug. 2016

\section{Keywords:}

Nurses, Disaster, Content analysis, Qualitative study

\begin{abstract}
Background: Awareness of nurses' experiences is helpful to identify current problems in providing services during disasters. In this regard, better planning and preparation may reduce the problems of this large group of health care providers. This study aimed to investigate the experiences of female nurses in providing services during disasters.

Materials and Methods: This is a qualitative study with content analysis approach. The participants comprised 15 nurses with experience in providing healthcare services during disasters. Samples were recruited by purposive sampling method and sampling was continued until data saturation. Data were collected through semi-structured interviews, then analyzed by manifest content analysis.
\end{abstract}

Results: Based on experiences and perceptions of nurses, three main categories found out of analyses of the obtained data were as follows: "the importance of paying attention to the specific needs of female nurses," "places for female nurses during disastrous period," and "the importance of the presence of female nurses in providing services."

Conclusion: Many factors affect the services delivered by female nurses. The results of this study showed that the specific needs of female nurses, who are the main body of Iranian nurses, could maximize their performance and minimize their psychological and emotional damages.

\section{Introduction}

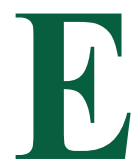

very year, many incidents happen all over the world, at least some of them accompany with severe financial, physical and psychological side effects [1]. The World Health Organization (WHO) defines incidents as natural or man-made disasters endangering dignity and human respect, which makes it necessary to get help and support in establishing the normal life [2].

Natural disasters are among the most important issues that the involved community bear severe casualties and financial losses. According to 2012 report of Research Centre of Epidemiology of Disasters, 357 natural disasters happened all over the world in this year, in which 9600 people died, 122.9 millions became victims, and

\section{* Corresponding Author:}

Hamid Reza Khankeh, PhD

Address: Department of Health in Emergencies and Disasters, University of Social Welfare \& Rehabilitation Sciences, Tehran, Iran

E-mail: Hamid.khankeh@ki.se 
the economic losses were 157.3 billion US dollars [1] Because of various geographical, economic, cultural, and political features and conditions, Iran has experienced lots of incidents due to human factors, in addition to natural disasters during the ages. When it comes to the occurrence of natural disasters, $90 \%$ of Iranian population is at the risk of earthquakes and floods $[3,4]$.

In many areas of the country, various disasters such as floods, earthquakes, landslides, and avalanches are always taking place. Almost every ten years, an earthquake with a great magnitude occurs in some areas of the country. It is remarkable to mention that Tehran, the capital city, with more than 10 million population, is located in an area greatly under the risk of earthquake. Since the natural disasters endanger the health and well-being of the society, delivering proper services is considered the main factor in surviving lives and reducing casualties, and also providing them with well-being after the occurrence of such incidents [5]. In these situations, we need a quicker response than normal ones $[6,7]$.

Natural disasters are special situations in need of the cooperation of all trained members of health team; because the health care team, especially nurses, are the first to be involved in such cases [8-11]. Nurses play active roles in managing natural disasters since they spend most of their time with patients. Their caring role made them trusted members of the community. Also they possess necessary expertise in providing clinical care, leading the team, delivering creative problem-solving skills, managing resource, and having important communicative skills most needed in such situations with rapid changes [12].

Since nurses are the first and the largest group to provide cares during natural disasters, they must be prepared, educated, qualified, experienced, knowledgabe, skillful, decisive, and self-confident [12-14]. Thus, it is really significant to consider the experiences of these people. The previous studies and experiences show that women are among the vulnerable population [15]. Due to their physical and physiological characteristics, and their role in their families, women have different experiences from men in these situations [16]. Social conditions of communities, especially in traditional ones, with patriarchal attitudes, cause women to be considered as dependent people who are unable to manage themselves or any other ones [17].

Gender-based violence, as a military weapon used in ethnical, racial, tribal, and religious conflicts, is another problem which make women even more predispose to damages [18]. Studies have shown that no organized as- sessment has conducted on women's needs during disasters and crises, which results in legal gaps in this area. The weak presence of women in govermental organizations in which most administrators, especially in the case of crisis management, are men, is led to the ignorance or at least inferiority of the needs of this vulnerable group $[18,19]$.

Regarding the importance of nurses as the first respondents to disasters, and their presence as the greatest part of the nursing system in our hospitals, the researchers studied the experiences of the nurses during disasters in Iran, to explain the presence of female nurses in the relief teams during disasters. Also, a clearer image of the experiences and difficulties of these female nurses in specific conditions like disasters and incidents, is provided that make a basis for health care policy makers of the country to plan for better services with higher quality.

\section{Materials and Methods}

Qualitative data analysis was used to analyze the study data which was a part of a bigger project done by grounded theory approach. Content analysis helps the researcher obtain concise and complete definitions of the studied phenomenon through reporting the concepts and subcategories [20]. A total of 15 participants were interviewed during 15 months (from February 2013 to April 2014) to gather rich data. The number of participants is decided by saturated data. Data gathering continued, in effect, till no new code or concept, emerged and the findings after $15^{\text {th }}$ participant were repetitious.

Then the researchers announced the end of data collection. Participants comprised nurses with the experience of working in disasters, nurses who had administrative role during this time, and some faculties at universities with expertise in natural disasters. Samples were recurited by purposive sampling method. To comply with maximum flexibility, we tried to choose those nurses who had served in natural disasters and also in different job positions. Interviews lasted between 34 and 88 minutes. Most interviews were done at work or home, according to the participants' wishes, in a calm and relaxing environment.

To collect data, we started each interview in a semistructured way with an open question in relation to the major question of the study. Then, according to data analysis, we continued with deep-digging and followup questions about their experiences of what happened to them. Some questions were as follows: "Please relate your last experience about the disaster you were in?", "What were your problems during the disaster?", "What 
did you do to solve them?", "How would you do your job if there were not such problems?" All interviews were done by the first author, recorded on an MP3 player with participant's permission.

Data analysis was done simultaneous with their collection, in several steps. First the recorded interviews were transcribed verbatim. In the second step, before coding, each text was read several times to get familiar with its content. In the third step, each semantic unit was chosen and coded. Then, in next step, codes were reviewed (codes were compared for their similarities and differences, to combine the similar ones), categorized, and expanded according to their similarities and suitability. Afterwards, the categories were once again reviewed and compared to the data to be sure about the consistency of the codes. Finally, the themes were identified by deep and careful thinking. In the last step, the categories were compared and the results were reported.

A set of categories, subcategories, and codes were formed out of the first interviews; and the emerging codes came finally into account. In order to increase data reliability, the researchers were continuously involved with the data for more than one year. All interview texts and all themes were reviewed several times by researchers who were qualified in qualitative research. After each coding, the text of interview was shown to the participant to approve its content. On the other hand, to verify the data, each part of the categories was shown to two colleagues familiar with and qualified in qualitative research; then their ideas were compared, and if similar, the result was accepted.

To assess the whole study procedure, the researcher saved and reported the whole procedure and methodology, deeply and accurately, to provide research followup for everyone. To convey the findings, the effort was made to relate all participants' words in the same way they were uttered. Sampling with maximum diversity helped having better data suitability.

This study was approved by Ethics Committee of Social Welfare and Rehabilitation Sciences, Tehran University, Tehran, Iran. All participants were fully informed about the aims of the study, and ensured about their confidentiality. The interviews were recorded with the participants' permissions. All participants had signed informed consent forms and were allowed to leave the study whenever they wanted.

\section{Results}

The study participants were 15 nurses with the average age of 40.8 years, with experiences in giving services or managing during recent disasters. Demographic characteristics of participants are shown in Table 1.

After analyzing the data, three themes were defined as: "paying attention to special needs of female nurses," "places for female nurses during disasters," and "the importance of female nurses' presence in relief teams." Below, the themes and their concepts are defined.

\section{Paying attention to special needs of female nurses}

The study participants mentioned the issues specific to female nurses, and considered the gender-related problems. In this regard, 6 subthemes were mentioned as follows: "paying attention to women's needs," "suitability to female nurses' personality," "cultural problems of female nurses in observing their coverings/ hijab," "female nurses' physical weakness," "nurses' harms at the scenes of a violent incidents," and "possible female nurses' sexual harms." Many participants, either man or woman, believed that female nurses need specific provisions at the scene of the incidents. Following disasters, lots of resources shortages occur which make the situation harder to work in. Meanwhile, women due to their specific feminine sensibility, require some special needs, which are not attended to or predicted at all in such situations, particularly in the first days of disasters.

"Women, for the specific conditions they have, in some points of crisis, cannot be useful in the area; $b$ 'cause they have some needs, you never thought of; as maybe there wasn't a female around, you never thought of. This's very important; we'd some women in our team; we'd lots of problems with 'em; first of all, their protection; second, they felt afraid; and third, their going to the ladies. "Said participant No.5.

The suitability of the female nurse's personality is another important aspect mentioned by many participants. Regarding the chaos, disorder, and the particular situation prevailing at the time of disaster, it is necessary to have nurses with proper personalities suitable to the situation. The incidents are difficult and complex situations which need strong people and powerful administers who can help the affected population. That is why characters with sensitive spirit are inappropriate for such times, and they should be avoided in such environments. 
Table 1. Demographic characteristics of the participants

\begin{tabular}{|c|c|c|c|}
\hline No. & Age (Years) & Position in Disaster Time & Work Experience (Years) \\
\hline 1 & 45 & Nurse, Nursing administrator & 18 \\
\hline 2 & 43 & Nurse, Nursing administrator & 18 \\
\hline 3 & 43 & Nurse, Nursing administrator & 22 \\
\hline 4 & 34 & Nurse & 8 \\
\hline 5 & 51 & Nurse & 23 \\
\hline 6 & 42 & Nurse & 13 \\
\hline 7 & 43 & Nurse, Nursing administrator & 17 \\
\hline 8 & 44 & Nurse, Nursing administrator & 16 \\
\hline 9 & 34 & Nurse & 11 \\
\hline 10 & 35 & Nurse & 9 \\
\hline 11 & 34 & Nurse & 10 \\
\hline 12 & 37 & Nurse & 12 \\
\hline 13 & 39 & Nurse & 11 \\
\hline 14 & 46 & Nurse, Nursing administrator & 20 \\
\hline 15 & 43 & Nurse, Nursing administrator & 23 \\
\hline
\end{tabular}

"You've to see if one's proper to come to the field or not. All aren't good to the job. Some we saw; some weren't ready, or their families don't let 'em gonna. So we've to choose those proper ones." Said participant No. 11.

"Me, as a woman, during disasters, I saw those comin' with no spirit for it. Yet no fear, I had, since a student at college, no problem; never bothered me; some ladies aren't really for such situations... no spirit for such a thing, so why comin' at all? Are you here to cry? You've to work; to be strong; and to help others. Not a place to sit and feel dep, or sorry. That's why I feel it's just a place for those spirited to come." Said participant No. 7.

Another problem, often mentioned by the participants in this study was the cultural problem for female nurses to keep their coverings/hijab. The importance of hijab in our culture is taken for granted, but normally not observed fully. It is really important for women to observe their hijab in all healthcare centers; yet, because of the unique characteristics of disaster time and in the incident area, it needs more attention to be given to. According to their experiences, female nurses had some problems in this regard.
"I don't agree to have women in the fields. After all, our culture's different. Women can't take care of their bodies. They can't observe their hijab, or their body; they may be unable to cover their bodies properly. So they make problems both for themselves and for others." Said participant No. 9.

“You know, I'm a true believer, but I've to say, there's no place for chador on your head, around there; you've to do many things at the same time; you've to serve a number of people at the same time, both men and women; so it's much better to've some dressing, covering enough, easy enough, to move around; which doesn't entangle you; as I am, there are dozens of things, problems, around us, women, with men here and there. Now you may've your hairs out of hijab, or your sleeve up enough to show your hand or your arm; pow... These're the things we see; it may seem foolish now to hear, yet each of these little things may make a trouble later on." Added participant No. 9.

Female nurses' physical weakness was another problem mentioned by many participants. Special situation of the incident requires lots of work in giving constant services for long period of hours; therefore, it is necessary in such 
times to be physically ready, besides having great qualifications in giving services. Women normally lack physical readiness, yet they do never think of its necessity, either. Mostly, there is not enough time, in their daily or weekly massive routines to spend on some physical activities.

"Ladies're normally week; they'ren't physically ready. Wow, I've seen some in Sweden, to hang from a heli; really amazin'; all've passed Rappel Surveyed courses. Here, our women, fall down before taking one or more steps. No kidding, they'ren't physically ready. Not ready any way. They never feel the necessity of making their bodies ready." Mentioned by participant No. 2 .

"Me, myself, didn't've the fitness the men had; not saying men're all ready, not all of'em, but women can't run even 2 minutes, in the scene; got out of breath soon; it's really important to get ready prior to it; do regular exercises, but for me, from one hand, my job, from the other hand, housework, my kid, or the like, then there's no more time to go to the gym for example; after all, is it important at all?" Said participant No. 10 in this regard.

The risk of injury in the scene of harsh incidents is another problem mentioned for the nurses by the participants. The nurses' experiences in the previous disasters show the incident scenes, with their special conditions, at times violent enough, increase the risk of injuries for those offering services. Meanwhile, the female nurses are more vulnerable and exposed to the dangers.

“Disaster field's a violent field; you've to be fit, your body, prepared; you may be injured every now and then; now if a woman, much worse's everything, women are more vulnerable in disaster scenes. "Said participant No. 10.

"The environment isn't a good one; from one hand, women's physical readiness isn't good enough; disaster scene's violent; you've to be kneaded; you've to have strong body; you may get injured every now and then; as I saw before, our women aren't physically ready enough." Said participant No. 4.

Another problem, most participants mentioned, is the risk of sexual harms to female nurses. According to their experiences in giving services during different disasters, female nurses expressed high risks of sexual harms to them, which are not necessarily limited to rape, but regarded invasion to their privacy as instances of this issue, too.

"Regardin' the situation of incidents, there also exists the possibility of sexual harms; we, women, are totally vulnerable to sexual harms in incidents. It'sn't the case that one wants to rape, or wants to sexually abuse; but culturally, any touch by men is bothering women." Said participant No. 8.

\section{Places for female nurses during disasters}

Considering the participants' experiences in giving services during disasters, and analyzing data obtained in this study, the researchers came to a concept, namely, "the place for female nurses," referring to places where they offer their services. By their experiences, it is very important to have female nurses at city hospitals, but as limited as possible at field hospitals. The explanation comes later.

The priority of having female nurses at city hospitals is one of the themes related to the concept of the presence of nurses in disasters. Many participants believed that if female nurses are settled in city hospitals and healthcare centers, they can be of greater help with less problems in giving services. Almost all nursing administers, and many experienced nurses, agreed that it would be much better to keep female nurses less involved in the scenes of incidents unless it is necessary.

"When we set up some field clinics, on condition of observin' these issues, it's good to have women; yet their vulnerability should be considered; and much better to be in small number. Say, Bam had a condition we had to settle women in the field; $b$ 'cause the nearest hospital was $140 \mathrm{~km}$ away; and we couldn't move the injured women this far; we'd to take ladies with ourselves, otherwise it was preferred to be just there." Said participant No.1.

"Ladies, during disaster times, are better to work at hospitals, rather than the fields; they've less problems this way." Said participant No. 9.

"If a lady's to work in the field hospital, she's to be trained, but fully controlled. Full of considerations. Not as many as men. The number of male nurses is now getting fewer these days. It must be thought of. To have men in the filed hospitals is preferred." Said participant No. 12.

The importance of female nurses' presence in the relief teams

Another concept, found after data analysis is the importance of female nurses' presence in the teams offering services. It refers to the situations in which, though lots problems with women during periods of disaster, their presence is so important that cannot be ignored. There are two subcategories for it: "female nurses as relaxing ele- 
ments in team," and "female nurses as creators of a sense of security in the injured." The definition will come later.

Female nurses as relaxing elements for the team, was a theme introduced after data analysis. According to the participants' experiences, the presence of women mitigated the unpleasant male atmosphere and brought a sense of relaxation to the people. As the experiences of the participants showed, it helped mitigate difficulties normally occur among those providing services for a long period of time in incidents.

"You may've kids among the injured, or women; you need women in your team, not many, just some. You know, I was in Bam; a kid was brought; we didn't know what t'do with it; it was under two years of age. It was the only remained from its family. We were lucky to have a female psychologist there. We gave it to her. None knew nothing to do now with the kid; nothing at all. It wasn't a good time; we didn't feel good about. We felt bad. Well, we can't be like mums. That nice female psychologist helped us out of that bewilderment." Explained participant No. 14 .

Female nurses, as creators of a sense of security among injured, was another related concept of their presence during disaster. Participants mentioned the importance of presence of female nurses to give services to injured women and kids as a natural need in such situations.

"Well, injured women may've difficulties to be exposed to men; they'd like to have women around, to help'em. There times, the disaster field is far, far from the first hospital; so you need to set field hospital. Women've some special needs; so wish a women around to help'em; so there must be a female nurse." Said participant No. 7.

"There're some injured women. Havin' a woman in your team brings a feel of security to the injured. All in all, a nurse, from your own gender, feels good; in Rudbar for example, we'd such a thing. We needed women in the scene; well there were injured women, with their special culture, they didn't wish to have men to help'em. There was the same thing in Azerbaijan, too." Added participant No. 9.

\section{Discussion}

In this study, three basic themes are as follows: "paying attention to special needs of female nurses," "places for female nurses during disasters," and "the importance of female nurses' presence in relief teams." These concepts show the difficulties and problems female nurses experienced during disasters and giving services to the injured. Some themes have some subthemes categorized in a group according to their features.

The study results show that the first theme, "paying attention to special needs of female nurses," consists of 6 subthemes of "paying attention to women's needs," "suitability to female nurses' personality," "cultural problems of female nurses in observing their coverings/ hijab," "female nurses' physical weakness," "nurses' damages at the scenes of a violent incidents," and "possible female nurses' sexual harms." The previous studies and experiences of disasters have shown that women are among the vulnerable population [15].

Their physical and physiological characteristics, together with their roles in families and society, have given them experiences different from men. Jahangiri mentioned in his study that lack of presence or weak appearance of female managers and experts in the field of natural disasters and crisis management have led to ignorance of women and their needs in the cycle of crisis management. For example, physiologic conditions of women would change after the stressful incidents such as natural disasters; and this change brings about some needs of special medications and hygiene supplies. The experiences from 1990 Rudbar earthquake showed that a significant number of women had abnormal uterine bleeding because of feeling stressed after earthquake; so they needed sanitary pads and contraceptive pills to stop the bleeding. But none of these items were considered in the list of medications and tools sent to the field [18].

Nakhaei, too, showed in his study the problems and difficulties women had during the time of disasters; and considered them more sensitive and more vulnerable than men; the results of his study show the importance of considering the special needs of women during disasters [21]. Thomas et al. in their book, Social Vulnerability during Disasters, explain some points about special characteristics of women in the ground of the problems female nurses may experience while giving services during disasters which are similar to those found about Iranian nurses in the very study [22].

Places for female nurses during disasters was another theme found in this study. Lack of training centers for women rescuer to teach the members and volunteers specialized training in relief and rescue is another issue which is responsible for low number of prepared women to be sent to the field. It is necessary to consider the problem of settling female rescuers in operational zone. The problem can be solved by creating a security belt 
by trained military forces to prevent the influx of people coming from neighboring regions $[18,19]$.

It is possible to solve the specific problems of women by strengthening the responsible, formal, and active presence of women in the crisis management structure, and participation of their delegates in the processes of decision making, policy making, and planning with the consideration given to women' needs through their membership in the teams of crisis managements, especially at the headquarters of the provincial disaster preparation; and finally providing workgroups for preparation, education, permanent settlement, healthcare, treatment, and reconstruction [15].

Another theme obtained from this study was "the importance of the presence of female nurses in the relief teams." The theme consists of two subthemes: "female nurses as relaxing elements in team," and "female nurses as creators of a sense of security in the injured." While talking about rescue team, Jahangiri stated that there was no need to have women, necessarily in relief and rescue specialized areas, but they might efficiently act as coordinators, mediators, and officers in charge of follow-up and documentation. Meanwhile, the presence of women is of great help for psychological support of the survivors, specifically in emergent situations. The experience obtained from Bam earthquake showed that dispatched men rescuers were not able to make proper emotional relationship with women and children, yet female rescuers, though very small in number, easily made communications and attracted their confidence [18].

Creating specialized women workgroups, like any other workgroups; preparing a suitable data bank about people and organizations able to help women during disasters, in order to prevent any parallel job, together with proper budgeting for using them in required time; activating female psychological supports; establishing a center for specialized scientific education for women and treating female specialized groups and female rescuers; developing specific training programs, especially for women, and allocating part of the funds of event headquarter and crisis management organization to the plans, especially for women during disasters, regarding their specific needs, are all among some strategies which can reduce the harms for women in such situations [15].

This study generally showed that the female nurses are affected with different parameters while giving services in disasters. Three main themes were recognized here which were the most important problems and concerns of female nurses during disasters. The nurses are often expected to work in noisy, crowded, chaotic, and distorted environments to give services to the injured; therefore, they confront with lots of challenges and troubles. The study results show that those nurses who were better prepared and comprehended to work in situations different from normal ones are better able to help and give services. It is also found that recognizing numerous problems that female nurses may confront in disasters, and providing them with their requirements, are important and necessary to maximize the tasks and services they can offer and to minimize their psychological harms.

Since our research studied the experiences of the nurses who gave services during previous disasters and was not at the time of disaster itself, a study limitation might be the problem of recalling all related data from the participants' memories. It is suggested that such studies be repeated during live disasters and also conduct more qualitative studies to consider the readiness of female nurses by grounded theory approach.

\section{Conclusion}

This study showed that the female nurses are affected by different parameters while giving services in disasters. Three of the most important of them were recognized in the present paper. Nurses are often expected to work in noisy, crowded, chaotic, and distorted environments to give services to the injured; therefore, they confront with lots of challenges and troubles. The study results show that the nurses who were better prepared and comprehended to work in situations different from normal ones are better able to help and give services.

It was also found that recognizing numerous problems female nurses may confront in disasters and providing them with their requirements are important and necessary. This may maximize the tasks and services they can offer and minimize their psychological harms. Since our research studied the experiences of the nurses who gave services during previous disasters and was not at the time of disaster itself, a study limitation might be the problem of recalling all related data from the participants' memories. It is suggested that such studies be repeated during live disasters and also conduct more qualitative studies to consider the preparedness of female nurses by grounded theory approach.

\section{Acknowledgements}

The authors sincerely thank the Vice President of the University of Social Welfare and Rehabilitation Sci- 
ences, Tehran, Iran, for financial support, and also all the nurses who took part in this study.

\section{Conflict of Interest}

The authors declared no conflict of interests.

\section{References}

[1] Guha-Sapir D, Hoyois P, Below R. Annual disaster statistical review 2013: The numbers and trends. Brussels. Centre for Research on the Epidemiology of Disasters; 2014.

[2] Usher K, Mayner L. Disaster nursing: A descriptive survey of Australian undergraduate nursing curricula. Australian Emergency Nursing Journal 2011; 14(2):75-80. doi: 10.1016/j. aenj.2011.02.005

[3] Guha-Sapir D, Hoyois P, Below R. Annual disaster statistical review 2012: The numbers and trends. Brussels: Centre for Research on the Epidemiology of Disasters; 2013.

[4] Pourvakhshoori N, Norouzi K, Ahmadi F, Hosseini MA Khankeh HR. Nursing in disasters: A review of existing models (Article in Press). International Emergency Nursing; 2016. doi: 10.1016/j.ienj.2016.06.004

[5] Jennings-Saunders A. Teaching disaster nursing by utilizing the Jennings Disaster Nursing Management Model. Nurse Education in Practice. 2004; 4(1):69-76. doi: 10.1016/s14715953(03)00007-6

[6] Conlon L WR. Preparing nurses for future disasters-The Sichuan experience. Australian Emergency Nursing Journal 2011; 14(4):246-50. doi: 10.1016/j.aenj.2011.08.001

[7] Slepski LA. Emergency preparedness and professional competency among health care providers during hurricanes Katrina and Rita: Pilot study results. Disaster Management \& Response. 2007; 5(4):99-110. doi: 10.1016/j.dmr.2007.08.001

[8] Magnaye B MM, Munoz MAF, Munoz RGV, Muro, JHM The role, preparedness and management of nurses during disasters. E-International Scientific Research Journal. 2014; 3(4):1749-2014

[9] Weiner E IM, Trangenstein P, Gordon J. Emergency preparedness curriculum in nursing schools in the United States. Prehospital and Disaster Medicine. 2005; 20(1):36-37. doi $10.1017 /$ s1049023x0001267x

[10] Veenema TG. Disaster nursing and emergency preparedness for chemical, biological, and radiological terrorism and other hazards. New York: Springer; 2003.

[11] Kaplan BG, Connor A, Ferranti EP, Holmes L, Spencer L. Use of an emergency preparedness disaster simulation with undergraduate nursing students. Public Health Nursing. 2011; 29(1):44-51. doi: 10.1111/j.1525-1446.2011.00960.x

[12] Gebbie K, \& Qureshi, K. Emergency and disaster preparedness: Core competencies for nurses. American Journal of Nursing. 2002; 102(1):46-51. doi: 10.1097/00000446200201000-00023
[13] Usher K. Are we ready? Preparing nurses to respond to disasters and emerging infectious diseases. Journal of Clinical Nursing. 2010; 19(11-12):1483-4. doi: 10.1111/j.13652702.2009.02979.x

[14] World Health Organization. Development of disaster preparedness toolkit for nursing and midwifery. Geneva: World Health Oraganization; 2013.

[15] Montano S, Savitt A. Rethinking our approach to gender and disasters: Needs, responsibilities, and solutions. Journal of emergency management (Weston, Mass). 2016; 14(3):18999. doi: $10.5055 /$ jem. 2016.0285

[16] Sohrabizadeh S, Tourani S, Khankeh HR. The gender analysis tools applied in natural disasters management: A Systematic Literature Review. PLOS. 2014; 6. doi: 10.1371/ currents.dis.5e98b6ce04a3f5f314a8462f60970aef

[17] Sohrabizadeh S. A qualitative study of violence against women after the recent disasters of Iran. Prehospital and disaster medicine. 2016; 31(4):407-12. doi: 10.1017/ s1049023x16000431

[18] Jahangiri K, Sadighi J. [Vulnerability analysis of women's health in disasters and recommended strategies for risk reduction: A qualitative study (Persian)]. Journal of Rescue \& Relief. 2011;3(1-2):60-6

[19] Enarson E, Chakrabarti PGD. Women, gender and disaster; global issues and initiatives. London: Sage Publications; 2010

[20] Elo S, Kyngäs H. The qualitative content analysis process. Journal of Advanced Nursing. 2008; 62(1):107-15. doi: 10.1111/j.1365-2648.2007.04569.x

[21] Nakhaei M, Khankeh HR, Masoumi GR, Hosseini MA Parsa-Yekta Z, Kurland L, et al. Impact of disaster on women in Iran and implication for emergency nurses volunteering to provide urgent humanitarian aid relief: A qualitative study. Australasian Emergency Nursing Journal. 2015; 18(3):165-72 doi: 10.1016/j.aenj.2015.02.002

[22] Thomas DSK, Phillips BD, Lovekamp WE, Fothergill A. Socia vulnerability to disasters. $2^{\text {nd }}$ ed. Philadelphia: CRC Press; 2012. 